\title{
Intercropping Induces Changes in Specific Secondary Metabolite Concentration in Ethiopian Kale (Brassica carinata) and African Nightshade (Solanum scabrum) under Controlled Conditions
}

\author{
Benard Ngwene ${ }^{1 *}$, Susanne Neugart ${ }^{1}$, Susanne Baldermann ${ }^{1,2}$, Beena Ravi ${ }^{1,3}$ and \\ Monika Schreiner ${ }^{1}$
}

${ }^{1}$ Leibniz Institute of Vegetable and Ornamental Crops, Großbeeren, Germany, ${ }^{2}$ Institute of Nutritional Science, University of Potsdam, Potsdam, Germany, ${ }^{3}$ Department of Crop and Animal Sciences, Humboldt University of Berlin, Berlin, Germany

OPEN ACCESS

Edited by:

Hussein Shimelis,

University of KwaZulu-Natal,

South Africa

Reviewed by:

Samson Tesfay,

University of KwaZulu-Natal,

South Africa

Georgia Ntatsi,

Agricultural University of Athens,

Greece

*Correspondence:

Benard Ngwene

ngwene@igzev.de

Specialty section:

This article was submitted to

Crop Science and Horticulture,

a section of the journal

Frontiers in Plant Science

Received: 07 June 2017 Accepted: 15 September 2017

Published: 29 September 2017

Citation:

Ngwene B, Neugart $S$,

Baldermann S, Ravi B and

Schreiner M (2017) Intercropping

Induces Changes in Specific

Secondary Metabolite Concentration

in Ethiopian Kale (Brassica carinata)

and African Nightshade (Solanum

scabrum) under Controlled

Conditions. Front. Plant Sci. 8:1700.

doi: 10.3389/fpls.2017.01700
Intercropping is widespread in small-holder farming systems in tropical regions and is also practiced in the cultivation of indigenous vegetables, to alleviate the multiple burdens of malnutrition. Due to interspecific competition and/or complementation between intercrops, intercropping may lead to changes in plants accumulation of minerals and secondary metabolites and hence, alter nutritional quality for consumers. Intercropping aims to intensify land productivity, while ensuring that nutritional quality is not compromised. This study aimed to investigate changes in minerals and secondary plant metabolites in intercropped Brassica carinata and Solanum scabrum, two important African indigenous vegetables, and evaluated the suitability of this combination for dryer areas. B. carinata and S. scabrum were grown for 6 weeks under controlled conditions in a greenhouse trial. Large rootboxes (8000 $\mathrm{cm}^{3}$ volume) were specifically designed for this experiment. Each rootbox was planted with two plants, either of the same plant species (mono) or one of each plant species (mixed). A quartz sand/soil substrate was used and fertilized adequately for optimal plant growth. During the last 4 weeks of the experiment, the plants were either supplied with optimal (65\% WHC) or low (30\% WHC) irrigation, to test the effect of a late-season drought. Intercropping increased total glucosinolate content in $B$. carinata, while maintaining biomass production and the contents of other health related minerals in both $B$. carinata and S. scabrum. Moreover, low irrigation led to an increase in carotene accumulation in both mono and intercropped $S$. scabrum, but not in B. carinata, while the majority of kaempferol glycosides and hydroxycinnamic acid derivatives of both species were decreased by intercropping and drought treatment. This study indicates that some health-related phytochemicals can be modified by intercropping or late-season drought, but field validation of these results is necessary before definite recommendation can be made to stakeholders.

Keywords: intercropping, indigenous leafy vegetables, nutrition security, secondary plant metabolites, Brassica carinata, Solanum scabrum 


\section{INTRODUCTION}

Mixed cropping systems are practiced in many regions of the world in an attempt to intensify land productivity, and leverage the positive effects of biodiversity and better use of resources (AFSA, 2016). This practice is widespread in small holder farming systems in tropical regions (Lithourgidis et al., 2011) and also serve as a strategy to reduce agricultural risks through on-farm diversification (Olasantan, 2007; IFAD, 2011), due to lack of appropriate social security systems and other conventional risk mitigation possibilities. Intercropping also leads to improvement in soil fertility, conservation of soil and water, enhancement of microclimate conditions (Ehrmann and Ritz, 2014), and plant protection (Khan et al., 2010). Intercropping may also influence accumulation of minerals and secondary metabolites and hence, alters the nutritional quality mediated by interspecific competition and/or complementation (Inal et al., 2007; Li et al., 2014; Tong et al., 2015).

When practicing intercropping, farmers generally aim for yield improvement and/or stability (Hauggaard-Nielsen et al., 2008). However, quality attributes should not be compromised especially in vulnerable regions like in Sub-Saharan Africa (SSA). Research on intercropping in SSA has generally focused on grain legume/cereal mix (Raseduzzaman, 2016) to improve soil fertility, as legumes are known to fix atmospheric nitrogen and replenish soils of this mostly rare commodity, which benefits the intercropped cereal (staple) crop (Shen et al., 2012). In many parts of SSA nowadays, however, there is growing interest and focus on highly nutritious foods such as indigenous leafy vegetables (ILV) because of their potential to promote nutrition and health of the consumers (Yang and Keding, 2009; Cernansky, 2015; Baldermann et al., 2016).

Sub-Saharan Africa is the region of the world with the highest prevalence of malnutrition, with over 200 million people affected representing more than $20 \%$ of the population (FAO, 2015). Consequently, the United Nation's Sustainable Development Goals include as their second target the end of hunger and achieving food security and improved nutrition (Lartey, 2015). We are therefore faced with not only the challenge to produce enough food, but also to develop strategies to provide adequate nutrition to the population. This includes increased intake of minerals, vitamins, as well as health related secondary plant compounds.

Interestingly, nutritious ILVs are presently in vogue in many communities in SSA, and gaining popularity among consumers. In Kenya for example, ILVs are sold in large supermarkets in Nairobi, and seed companies are increasingly paying attention toward breeding traditional varieties (Cernansky, 2015). In these communities where foods of animal origin are not readily available, mainstreaming these nutritious ILVs into food systems to alleviate the multiple burdens of malnutrition has often been recommended (Abukutsa, 2010; Noorani et al., 2016). Such attempts should, however, exploit the multifunctionality of a mixed cropping systems (AFSA, 2016) advocated in such communities (Olasantan, 2007), and consider the nutritional changes that vegetables may undergo under such a system.
Ethiopian kale (Brassica carinata) is a leafy vegetable indigenous to East Africa, and gaining popularity in SSA. It is being advocated in urban and peri-urban horticulture in many parts of the African continent as a more nutritive alternative to Brassica oleracea (exotic counterpart) (Ambrose-Oji, 2009). It belongs to the order Brassicales which is characterized by a specific group of secondary plant metabolites - the glucosinolates (Verkerk et al., 2009). It has been shown that some break down products of glucosinolates - especially the isothiocyanates - possess anticancerogenic (Lippmann et al., 2014), anti-inflammatory (Herz et al., 2016) or antidiabetogenic (Guzmán-Pérez et al., 2016) properties. In addition to their richness in glucosinolates, B. carinata like other ILVs is rich in minerals and vitamins (Yang and Keding, 2009), and other secondary metabolites (flavonoids, carotenoids, and chlorophylls) (Neugart et al., 2017) possessing anti-oxidative properties and thus have the potential as natural sources for reducing cellular oxidative damage, and suppression of various cancers and cardiovascular diseases (Uusiku et al., 2010). Odongo et al. (2017) in a recent study highlighted the chemopreventive potential of B. carinata.

In one of the very few studies in SSA on intercropping Brassicals, the suitability of intercropping $B$. carinata with other ILVs (slender leaf (Crotalaria spp.), cowpea (Vigna unguiculata), African nightshade (S. scabrum), and spider plant (Cleome gynandra) was investigated (Oseko et al., 2006). They concluded that $V$. unguiculata and $S$. scabrum were suitable for intercropping with $B$. carinata. Their study was, however, focused on physiological investigations, and no consideration was put on nutritional and/or health promoting attributes that might be affected by intercropping. Both $V$. unguiculata and $S$. scabrum are considered quite nutritious but research-based evidence on the nutritional richness of $S$. scabrum is even more scarce even though it is one of the most popular ILV in some parts of SSA (Onyango and Imungi, 2007). While intercropping of $B$. carinata and S. scabrum may contribute to food and nutrition security in this region, it is important to understand nutritional changes that may occur under such systems.

In addition to changes induced by intercropping, plant biochemistry can also be affected by environmental factors like drought (Lisar et al., 2012), which is a very common phenomenon in SSA, and projected to increases with climate change alterations (Burke et al., 2009). Therefore large areas of production of these vegetables are presently, and will in future be affected by drought. Drought stress induces accumulation of reactive oxygen species (ROS) (Hasegawa et al., 2000). The accumulation of ROS may act as signals for inducing ROS scavengers and other protective mechanisms (Prasad et al., 1994). Drought induced oxidative damage in the plant tissue is controlled by a combined action of enzymatic and nonenzymatic antioxidant systems. Carotenes (e.g., $\beta$-carotene) form an important part of the plant antioxidant defense system. Apart from their role as accessory pigments, carotenes are effective antioxidant and contribute in protecting and sustaining photochemical processes (Havaux, 1998). Carotene accumulation in the plant is consequently influenced by plant water status. 
In the present study our objective was therefore to investigate changes in nutritional quality (minerals and secondary plant compounds focusing on glucosinolates, flavonoids, carotenoids, and chlorophylls) in leaves of these two important African ILVs (B. carinata and S. scabrum) as affected by intercropping. Additionally the suitability of the intercropping combination for dryer areas (drought treatment) was assessed, and the effect of a late-season drought on carotene accumulation was tested. Due to the difficulties in accurately managing water and fertilizer levels in the field, we decided for a greenhouse experiment to simulate these conditions.

\section{MATERIALS AND METHODS}

\section{Planting, Experimental Setup and Growth Conditions}

Seeds of B. carinata and S. scabrum obtained from the AVRDC Arusha, Tanzania were germinated in fine quartz sand for 1 week, when the primordial leaves were fully established. Two seedlings of the same crop (mono) or one of each crop (to simulate intercropping) were transplanted $15 \mathrm{~cm}$ apart in "rootboxes" (Figure 1). The rootboxes were constructed with $1 \mathrm{~cm}$ thick PVC plates (bottom and sides) and removable plexiglass plates (front and back). The internal dimension of the boxes was $20 \mathrm{~cm}$ (length), $10 \mathrm{~cm}$ (width), and $40 \mathrm{~cm}$ (depth) resulting in a total volume of $8000 \mathrm{~cm}^{3}$. Each rootbox was filled with a $50 / 50 \mathrm{v} / \mathrm{v}$ mixture of a soil substrate and coarse quartz sand. The soil substrate was a nutrient poor loamy sand, from the C-horizon of a luvisol, and had a $\mathrm{pH}$ of about 7.2. It was sieved through a $4 \mathrm{~mm}$ sieve, and fertilized with $200 \mathrm{mg} \mathrm{N}$ $\left(\mathrm{NH}_{4} \mathrm{NO}_{3}\right), 100 \mathrm{mg} \mathrm{P}\left(\mathrm{KH}_{2} \mathrm{PO}_{4}\right), 400 \mathrm{mg} \mathrm{K}\left(\mathrm{K}_{2} \mathrm{SO}_{4}\right), 200 \mathrm{mg}$ $\mathrm{Mg}\left(\mathrm{MgSO}_{4}\right), 20.8 \mathrm{mg} \mathrm{Fe}$ (Fe-EDTA), $20 \mathrm{mg} \mathrm{Zn}\left(\mathrm{ZnSO}_{4}\right), 20 \mathrm{mg}$ $\mathrm{Cu}\left(\mathrm{CuSO}_{4}\right) \mathrm{kg}^{-1}$ dry soil. This rate of fertilization was chosen based on previous experience with the soil substrate. The sides of the rootboxes were covered with an opaque plastic wrapping to prevent exposure to light. The rootboxes were arranged on a rack and inclined at $45^{\circ}$. The inclination was intended to encourage root growth toward and along the plexi-glass plates.

Water content in the mixed substrate was set at $65 \%$ water holding capacity (WHC) to ensure optimal water supply to the plants, and the plants were kept in a greenhouse. Water loss from the root-boxes was estimated gravimetrically and replaced regularly (once or twice daily). The experiment was set up in a completely randomized design and placed in a greenhouse in Grossbeeren, Germany (long. $13^{\circ} 19^{\prime} 60^{\prime} \mathrm{E}$; lat. $\left.51^{\circ} 22^{\prime} 0^{\prime} \mathrm{N}\right)$. The plants were grown under this irrigation regime for 2 weeks to well establish in the substrate before commencing of irrigation treatments. The irrigation treatments consisted of either maintaining optimal water supply $(65 \%$ WHC) to half of the mono and mixed treatments, or simulating drought treatment (30\% WHC) to the remaining half. The two factorial experiment therefore consisted of three cropping system treatments (mono B. carinata, mono S. scabrum, mixed B. carinatal S. scabrum), and two irrigation treatments $[65 \%$ (optimal supply) and 30\% (drought simulation) WHC]. The

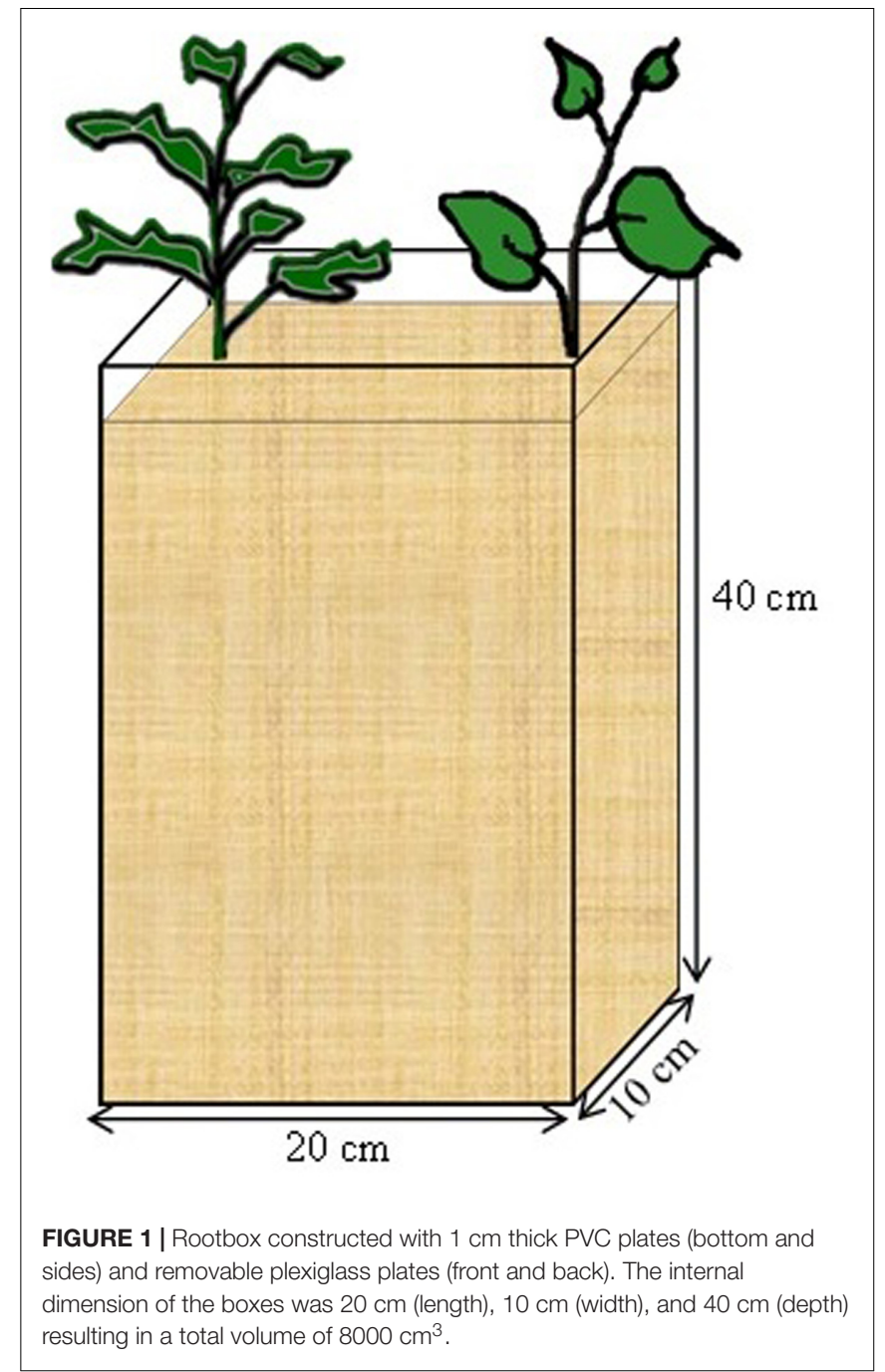

plants were further cultivated for 4 weeks during which the plants were irrigated with an automatic irrigation system (GARDENA Urlaubsbewässerung-Set; GARDENA Manufacturing $\mathrm{GmbH}$, Ulm, Germany), supplemented with gravimetric measurements. During cultivation, average day/night temperatures were $25^{\circ} \mathrm{C} / 20^{\circ} \mathrm{C}$, and relative humidity ranged from 52 to $83 \%$ with an average of $68 \%$. The experiment was conducted between May and July, and all treatments had four replicates.

Within the first 2 weeks of cultivation, root growth was monitored after every 4 days by tracing roots growing along the plexi-glass plates with a permanent marker. A different color was used for each measurement. The length of roots growing along the plexi-glass plates at each measurement was latter estimated using a digital map reader (Wayfinder MR H; Huger Electronics GmbH, Germany).

\section{Harvest}

Plants were harvested 6 weeks after transplanting. For each plant, all leaves were separated from the stem, the fresh weight (FW) was recorded, and frozen immediately. The frozen leaf material 
was later lyophilized at $-30^{\circ}$ for 1 week (CHRIST ALPHA; Martin Christ Gefriertrocknungsanlagen $\mathrm{GmbH}$, Osterode am Harz, Germany), ground and stored for subsequent mineral and metabolite analyses. All other plant material were dried in an oven at $65^{\circ} \mathrm{C}$ for 3 days and the dry weight (DW) was noted.

\section{Nutrient Analysis}

Sub samples of about $200 \mathrm{mg}$ of the pulverized leaf material were digested with concentrated (65\%) nitric acid and 30\% hydrogen peroxide ( 5 and $\mathrm{ml}$, respectively) for $15 \mathrm{~min}$ at $200^{\circ} \mathrm{C}$ in a microwave (MARSXpress 250/50; CEM Corporation, Matthews, NC, United States) and taken up to $25 \mathrm{ml}$ with distilled water. After filtration (Filter circles MN 615, Macherey-Nagel Germany), P concentration in the filtrate was analyzed colorimetrically with a spectrophotometer (EPOS 5060, Eppendorf, Hamburg Germany) at $436 \mathrm{~nm}$ wavelength after staining with ammonium-molybdate vanadate solution (Gericke and Kurmies, 1952). Ca, Mg and $\mathrm{Zn}$ concentrations were measured by atomic absorption spectrometry (AAS; ATI Unicam 939/Solaar, Thermo Electron, United States).

\section{Secondary Plant Metabolite Analysis Glucosinolate Analysis}

Glucosinolates in lyophilized powdered leaf sample were assessed as desulfo-glucosinolates by using the method according to Wiesner et al. (2013) with slight modifications described in Omondi et al. (2017).

\section{Flavonoid and Hydroxycinnamic Acid Analysis}

To analyze the phenolic compounds, $20 \mathrm{mg}$ lyophilized powdered leaf sample was extracted according to Neugart et al. (2015). For the quantitative analysis of flavonoid glycosides and hydroxycinnamic acid derivatives, an HPLC series 1100 (Agilent Technologies, Waldbronn, Germany) was used as described in Neugart et al. (2017). Standards (chlorogenic acid, quercetin 3glucoside, kaempferol 3-glucoside and; isorhamnetin-3-glucoside Roth, Karlsruhe, Germany) were used for external calibration curves in a semi-quantitative approach. Results are presented in $\mathrm{mg} \mathrm{g}^{-1} \mathrm{DW}$.

\section{Carotenoid and Chlorophyll Pigments Analysis}

Carotenoids and chlorophyll pigments were extracted from $5 \mathrm{mg}$ of lyophilized ground leaves with methanol tetrahydrofuran (MeOH:THF) solution (1:1 v:v, $500 \mu \mathrm{L}, 3$ times) until colorless by shaking at $1000 \mathrm{rpm}$ for $5 \mathrm{~min}$ and followed by centrifugation at $4500 \mathrm{rpm}$ for $5 \mathrm{~min}$. The combined supernatants were evaporated in a stream of nitrogen. The extracts were dissolved in $180 \mu \mathrm{L}$ isopropyl alcohol and $20 \mu \mathrm{L}$ dichloromethane. Prior to analysis the solutions were filtered through a $0.2 \mu \mathrm{M}$ polytetrafluoroethylene (PTFE) membrane and kept at $4^{\circ} \mathrm{C}$ during the analysis process. An Agilent Technologies 1290 Infinity UHPLC equipped with a diode array detector and 6230 TOF LC/MS with an APCI ion source was used for the analysis. The gas temperature was set to $325^{\circ} \mathrm{C}$ at a flow rate of $8 \mathrm{~L} \mathrm{~min}^{-1}$. The nebulizer and the vaporizer pressure was set to $35 \mathrm{psi}$ at a temperature of $350^{\circ} \mathrm{C}$. The ionization voltage was set to $+3500 \mathrm{~V}$ and a fragmentor voltage of $175 \mathrm{~V}$ was applied at a corona current of $6.5 \mu \mathrm{A}$. The separation was performed on a C30-stationary phase (YMC-Carotenoid, $100 \mathrm{~mm} \times 2.1 \mathrm{~mm}, 3 \mu \mathrm{m}$ YMC Co., Ltd., Japan) in gradient mode at a flow rate of $0.2 \mathrm{ml} \mathrm{min}^{-1}$. The mobile phases were composed of methanol, methyl-tert-butylether and water in different volume ratios (solvent A: 81/15/4 and solvent B: 6/90/4). Ammonium acetate $(20 \mathrm{mM})$ was added to the mobile phases to enhance the ionization. Identification was achieved based on retention times, absorption spectra and $\mathrm{m} / \mathrm{z}$ of the pseudo molecular ions as compared with authentic reference substances. External standard calibration was achieved by dose-response curves.

\section{Statistical Analysis}

All data were subjected to a two-way analysis of variance (ANOVA). The means were separated by a Tukey's HSD test $(P \leq 0.05)$. Values obtained from the two plants in each monoculture were averaged for each replicate before statistical analysis was performed $(n=4)$. Statistics were performed using the Statistica software (Statistica 13; Dell Inc., United States)

\section{RESULTS}

\section{Plant Growth}

Shoot DW of both B. carinata and S. scabrum were not significantly influenced by the cropping system, but by the irrigation treatment (Table 1). In the treatment supplied with low irrigation $\left(\mathrm{W}_{\text {low }}\right)$, shoot DW was reduced significantly in both crops. There was no distinct effect of intercropping on the total yield in both optimal irrigated $\left(\mathrm{W}_{\mathrm{opt}}\right)$ and low irrigated treatments. There was also no difference in root length growing along the plexi-glass plates during the first 2 weeks of the experiment (data not shown).

\section{Concentration of Mineral Nutrients}

Similar to shoot growth, cropping system did not have a significant effect on mineral nutrient concentration in leaves except for $\mathrm{Zn}$ concentration in B. carinata. Irrigation, however, significantly influenced leaf concentration of $\mathrm{Ca}$ and $\mathrm{P}$ in B. carinata, and $\mathrm{Mg}, \mathrm{P}$ and $\mathrm{Zn}$ in S. scabrum according to the twoway ANOVA (Table 2). The individual effects (direct comparison with their well-watered counterparts) where, however, not very strong (Table 2).

\section{Concentration of Secondary Plant Metabolites \\ Glucosinolate}

As glucosinolates are secondary plant metabolites which are limited to the order Brassicales, they were identified only in B. carinata.

The predominant glucosinolate in the leaves was 2-propenyl glucosinolate and it was the only detected aliphatic glucosinolate. Leaf concentration of 2-propenyl glucosinolate contributed to over $95 \%$ of total glucosinolate and was significantly increased by intercropping under optimal irrigation conditions (Figure 2) compared to sole cropping. Also the indole 3-indolylmethyl 
TABLE 1 | Shoot dry weight of $B$. carinata and $S$. scabrum at harvest (g/plant).

\begin{tabular}{|c|c|c|c|c|c|c|}
\hline \multirow[b]{2}{*}{ Crop } & \multirow[b]{2}{*}{ Irrigation } & \multicolumn{2}{|c|}{ Shoot dry weight (g) } & \multicolumn{3}{|c|}{ Significant tests } \\
\hline & & Mono & Mixed & $c$ & $I$ & $C \times I$ \\
\hline \multirow[t]{2}{*}{ B. carinata } & $W_{\text {opt. }}$ & $9.12 \pm 0.48 b$ & $8.28 \pm 1.03 b$ & ns & $*$ & ns \\
\hline & $W_{\text {low }}$ & $6.31 \pm 0.68 a$ & $5.87 \pm 0.68 a$ & & & \\
\hline \multirow[t]{2}{*}{ S. scabrum } & $W_{\text {opt. }}$ & $8.16 \pm 0.51 a$ & $9.22 \pm 2.45 a$ & ns & $*$ & ns \\
\hline & $W_{\text {low }}$ & $6.31 \pm 0.64 a$ & $6.41 \pm 1.24 a$ & & & \\
\hline
\end{tabular}

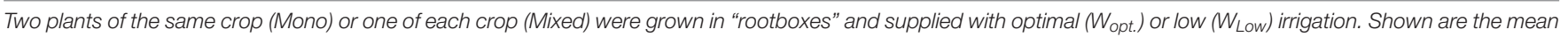

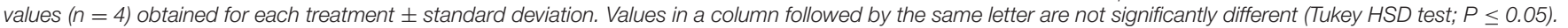

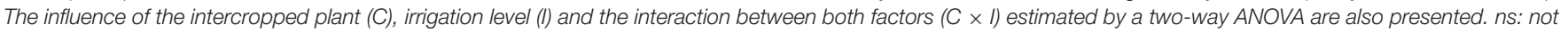
significant; *: significant at $P \leq 0.05$.

TABLE 2 | Concentration of Ca, Mg, P and Zn in B. carinata and S. scabrum leaves at harvest.

\begin{tabular}{|c|c|c|c|c|c|c|c|c|c|}
\hline \multirow[b]{2}{*}{ Crop } & \multirow[b]{2}{*}{ Irrigation } & \multicolumn{2}{|c|}{$\mathrm{Ca}(\mathrm{mg} / \mathrm{g})$} & \multicolumn{2}{|c|}{$M g(m g / g)$} & \multicolumn{2}{|c|}{$P(\mathrm{mg} / \mathrm{g})$} & \multicolumn{2}{|c|}{$\mathrm{Zn}(\mu \mathrm{g} / \mathrm{g})$} \\
\hline & & Mono & Mixed & Mono & Mixed & Mono & Mixed & Mono & Mixed \\
\hline \multirow[t]{2}{*}{ B. carinata } & Wopt. $_{\text {op }}$ & $31.97 a \pm 2.9$ & $33.27 a \pm 3.6$ & $6.24 a \pm 0.43$ & $5.93 a \pm 0.51$ & $2.85 a \pm 0.10$ & $2.95 a \pm 0.19$ & $137.2 \mathrm{a} \pm 5.3$ & $112.2 \mathrm{a} \pm 15.2$ \\
\hline & $W_{\text {low }}$ & $30.42 a \pm 3.0$ & $27.62 \mathrm{a} \pm 2.9$ & $6.14 a \pm 0.37$ & $5.69 a \pm 0.13$ & $2.55 a \pm 0.17$ & $2.56 a \pm 0.34$ & $136.7 \mathrm{a} \pm 10.6$ & $126.6 \mathrm{a} \pm 17.4$ \\
\hline \multirow[t]{2}{*}{ S. scabrum } & $W_{\text {opt. }}$ & $23.92 \mathrm{a} \pm 7.0$ & $21.06 a \pm 3.0$ & $5.99 a b \pm 1.36$ & $5.61 a \pm 0.85$ & $2.83 a \pm 0.33$ & $2.83 a \pm 0.12$ & $158.4 b \pm 20.7$ & $151.4 b \pm 7.4$ \\
\hline & $W_{\text {low }}$ & $22.76 a \pm 1.6$ & $23.85 a \pm 2.8$ & $6.76 \mathrm{ab} \pm 0.47$ & $7.32 b \pm 0.67$ & $2.49 a \pm 0.14$ & $2.66 a \pm 0.28$ & $115.3 a \pm 10.8$ & $135.6 \mathrm{ab} \pm 12.9$ \\
\hline
\end{tabular}

Significant tests for $B$. carinata

Cropping $(C)$
Irrigation $(l)$
$C \times I$

$\begin{array}{ll}\mathrm{ns} & \mathrm{ns} \\ * & \mathrm{~ns} \\ \mathrm{~ns} & \mathrm{~ns}\end{array}$

$\begin{array}{ll}\mathrm{ns} & * \\ * & \mathrm{~ns} \\ \mathrm{~ns} & \mathrm{~ns}\end{array}$

Significant tests for S. scabrum

$\begin{array}{llcc}\text { Cropping }(C) & \mathrm{ns} & \mathrm{ns} & \mathrm{ns} \\ \text { Irrigation }(l) & \mathrm{ns} & * & * \\ \mathrm{C} \times I & \mathrm{~ns} & \mathrm{~ns} & \mathrm{~ns}\end{array}$



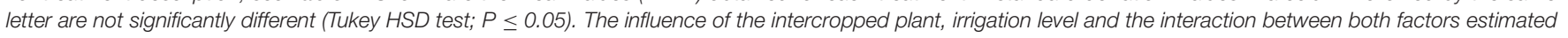
by a two-way ANOVA are also presented. ns: not significant; * : significant at $P \leq 0.05$.

glucosinolate was quantitatively determined as well as its derivatives were assessed, but only in trace concentrations (Table 3). The concentration of 4-Hydroxy-3-indolylmethyl glucosinolate and 4-methoxy-3-indolylmethyl glucosinolate were also significantly increased by intercropping compared to sole cropping, while neither intercropping nor the variation in water supply conditions showed an effect on their precursor, 3indolylmethyl glucosinolate, and the 1-methoxy-3-indolylmethyl glucosinolate (Table 3).

\section{Carotenoids}

In both crop species, $\beta$-carotene and lutein where the major carotenoids found. In $B$. carinata leaves, the concentration of both $\beta$-carotene and lutein were not influenced by either cropping system or irrigation treatment. In S. scabrum leaves, however, the concentration of both $\beta$-carotene and lutein were highly affected by the irrigation treatment (two-way ANOVA, $p<0.001$ in both cases). There were consistently higher in the $\mathrm{W}_{\text {low }}$ plants compared to the corresponding $\mathrm{W}_{\text {opt }}$ plants (Figure 3).

\section{Chlorophyll A and B}

In $B$. carinata leaves, chlorophyll A concentration was not affected by cropping system or level of irrigation. However, the concentration of chlorophyll $\mathrm{B}$ was affected by the level of irrigation, and there was an interaction between cropping system and irrigation treatment. Low irrigation significantly increased chlorophyll B concentration as compared to optimal irrigation (Table 4). In S. scabrum leaves the concentration of both chlorophyll A and B was affected by level of irrigation, with higher values for the $\mathrm{W}_{\text {low }}$ treatment as compared to the $\mathrm{W}_{\text {opt }}$ treatment. Additionally, there was an interaction between the two factors on the concentration of chlorophyll B (Table 4).

\section{Flavonoids}

The flavonoid glycosides and hydroxycinnamic acid derivative profiles of $B$. carinata and $S$. scabrum differ enormously (Neugart et al., 2017). B. carinata mainly has mono-alkylated kaempferol and isorhamnetin glycosides whereas $S$. scabrum contains mainly non-acylated quercetin glycosides. In $B$. carinata 13 out of 21 compounds mainly kaempferol glycosides were 


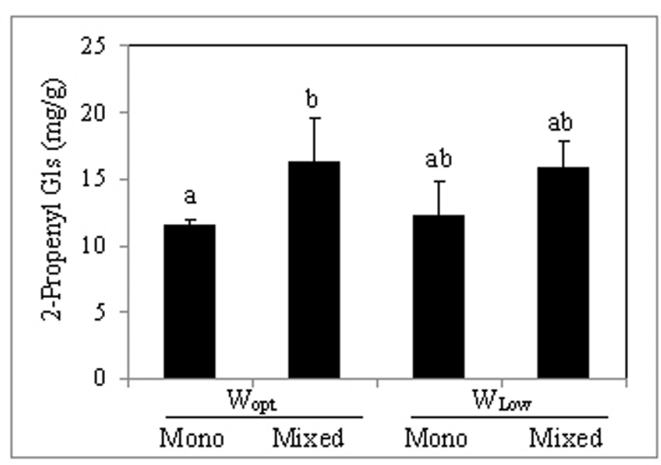

FIGURE 2 | 2-Propenyl glucosinolate concentration in B. carinata leaves (mg/g dry weight). For treatment description, see Table 1. Shown are the mean values $(n=4)$ obtained for each treatment + standard deviation. Bars followed by the same letter are not significantly different (Tukey HSD test; $P \leq 0.05)$.

significantly reduced by intercropping. Additionally, 13 out of 21 compounds were also reduced by the lower irrigation level, and were mainly hydroxycinnamic acid derivatives and kaempferol glycosides. There was only one interaction between intercropping and irrigation level for 3-caffeoylquinic acid (Supplementary Tables S1A-C). In contrast, in S. scabrum only 3 out of 22 compounds were significantly reduced by intercropping whereas 14 compounds mainly hydroxycinnamic acid derivatives were reduced by $\mathrm{W}_{\text {low }}$ compared to $\mathrm{W}_{\text {opt }}$ treatment, but no interaction was observed (Supplementary Tables S1D-F).

\section{DISCUSSION}

\section{Plant Growth and Mineral Element Uptake}

Intercropping had no effect on biomass production or mineral nutrient uptake and no clear belowground competition/complementation for mineral nutrient uptake was evident under our conditions. Plant growth (shoot biomass) was not affected by intercropping in both B. carinata and S. scabrum. While many studies have recorded yield improvement in mixed cropping systems (Shen et al., 2012; Wang et al., 2014; Raseduzzaman, 2016), related mostly to more efficient use of belowground resources, some studies have also reported no yield change (Oseko et al., 2006), or even yield reduction (Wang et al., 2007). These different outcomes are mostly due to the level of compatibility of the crops involved, and spatial and temporal availability of nutrients (Ehrmann and Ritz, 2014).

Most of the resources essential for plant growth are found belowground hence the main ecological processes defining the outcome of multiple cropping systems are the belowground competition for space and resources (Martin and Snaydon, 1982). Root distribution in the substrate (Zarea et al., 2009), and interactions therefore play a very important role in multiple cropping systems (Ehrmann and Ritz, 2014). In the present experiment, we did not observe any competition or complementarity between the B. carinata and the S. scabrum in terms of nutrient availability and use. This is indicated first in the results of root growth within the first part of the experiment, and second in the result of mineral nutrient uptake, where no difference was observed between sole- and inter-crops. The situation might be different in field grown crops where nutrient distribution and dynamics is not so homogeneous. Nevertheless, a similar result was obtained in the field by (Oseko et al., 2006) in intercropped B. carinata and S. scabrum.

While no competition for mineral nutrients was evident between the intercrops in this study, it is likely that there was adequate supply of nutrient in the substrate to support both plants. In conditions of nutrient limitation, mobilization processes are greater because of plant response and alteration of interspecific competition (Inal and Gunes, 2008). However, even when competition for nutrients is not evident in intercropping, there is nevertheless alteration in biological and chemical process in the rhizosphere (Inal et al., 2007) which can lead to changes in plant biochemistry.

In the absence of growth improvement though, the multifunctionality of a mixed cropping systems (AFSA, 2016) still prevails, as it ensures yield stability, diet diversify, and consequently improved nutrition (Frison, 2016; Uauy, 2016).

TABLE 3 | Indole glucosinolate concentration in B. carinata leaves at harvest.

\begin{tabular}{|c|c|c|c|c|c|c|c|c|}
\hline \multirow[b]{2}{*}{ Irrigation } & \multicolumn{2}{|c|}{ I3M (mg/g) } & \multicolumn{2}{|c|}{ 4OHI3M (mg/g) } & \multicolumn{2}{|c|}{ 1MOI3M (mg/g) } & \multicolumn{2}{|c|}{ 4MOI3M (mg/g) } \\
\hline & Mono & Mixed & Mono & Mixed & Mono & Mixed & Mono & Mixed \\
\hline Wlow & $0.12 a \pm 0.02$ & $0.16 a \pm 0.04$ & $0.13 a b \pm 0.05$ & $0.18 b \pm 0.03$ & $0.021 a \pm 0.006$ & $0.023 a \pm 0.006$ & $0.008 a b \pm 0.005$ & $0.003 a \pm 0.002$ \\
\hline
\end{tabular}

\section{Significant tests}

Cropping (C)

Irrigation (I)

$C \times 1$ ns

ns ns

ns

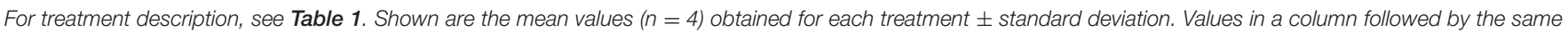

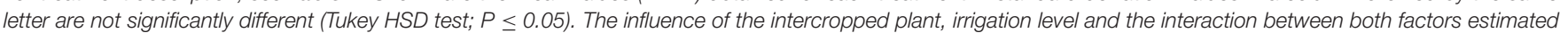

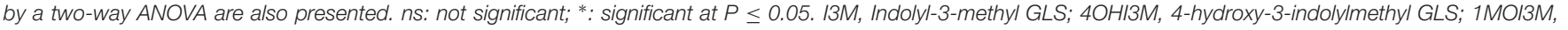
1-methoxy-3-indolylmethyl GLS; 4MOI3M, 4-methoxy-3-indolylmethyl GLS. 


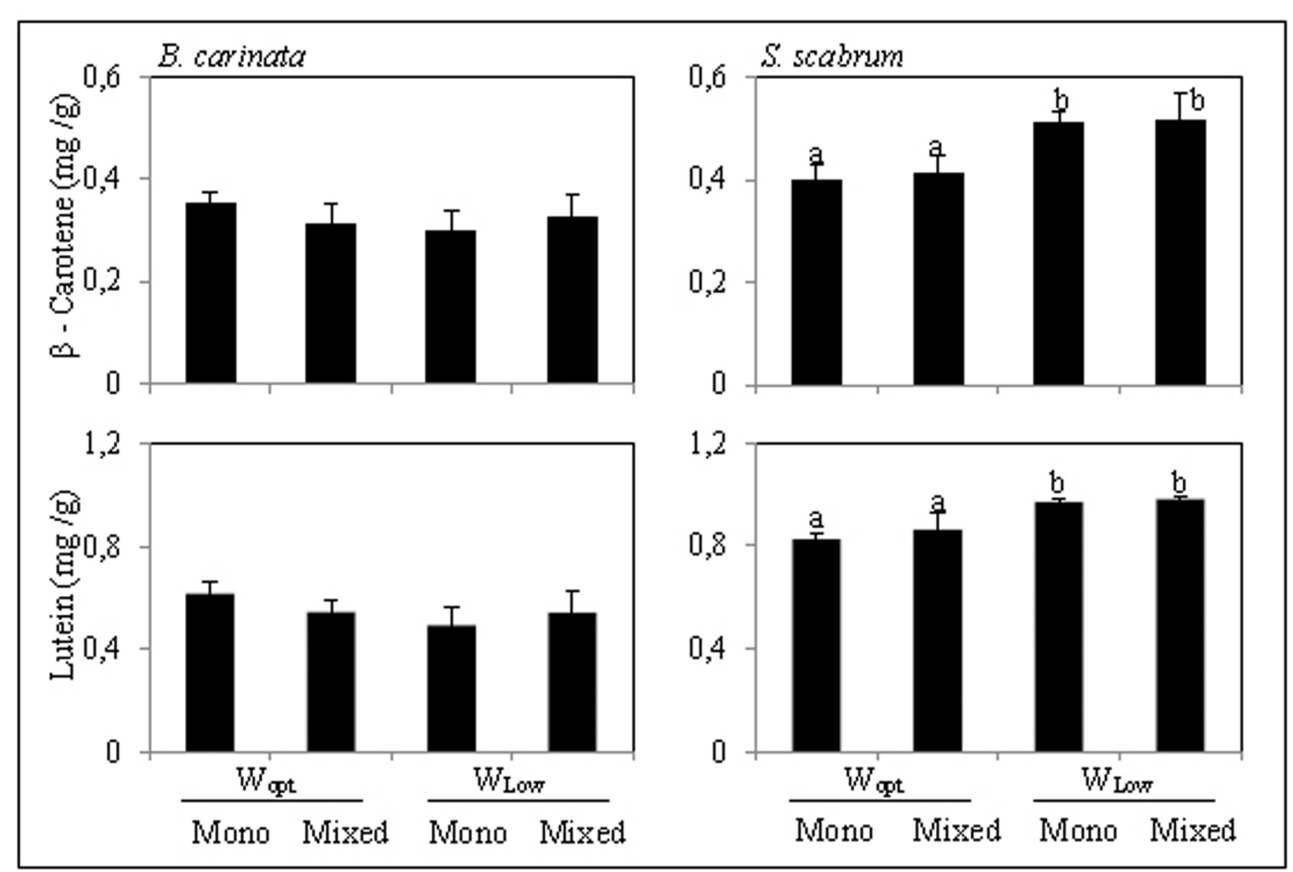

FIGURE 3 | $\beta$-Carotene and lutein concentration in B. carinata and S. scabrum leaves (mg/g dry weight). For treatment description, see Table 1. Presented are the mean values $(n=4)$ obtained for each treatment + standard deviation. Bars followed by different letters are significantly different (Tukey HSD test; $P \leq 0.05)$.

TABLE 4 | Chlorophyll A and B concentration in B. carinata and S. scabrum leaves at harvest.

\begin{tabular}{|c|c|c|c|c|c|}
\hline \multirow[b]{2}{*}{ Crop } & \multirow[b]{2}{*}{ Irrigation } & \multicolumn{2}{|c|}{ Chlorophyll A (mg/g) } & \multicolumn{2}{|c|}{ Chlorophyll B (mg/g) } \\
\hline & & Mono & Mixed & Mono & Mixed \\
\hline \multirow[t]{2}{*}{ B. carinata } & $W_{\text {opt. }}$ & $1.33 \pm 0.06 \mathrm{a}$ & $1.11 \pm 0.27 a$ & $0.64 \pm 0.12 b$ & $0.54 \pm 0.04 a b$ \\
\hline & $W_{\text {low }}$ & $1.01 \pm 0.30 \mathrm{a}$ & $1.01 \pm 0.24 a$ & $0.51 \pm 0.07 a$ & $0.54 \pm 0.08 \mathrm{ab}$ \\
\hline \multirow[t]{2}{*}{ S. scabrum } & $W_{\text {opt. }}$ & $1.40 \pm 0.12 a$ & $1.68 \pm 0.17 a b$ & $0.62 \pm 0.04 a$ & $0.67 \pm 0.04 a$ \\
\hline & $W_{\text {low }}$ & $1.89 \pm 0.24 b$ & $1.78 \pm 0.24 a b$ & $0.83 \pm 0.01 b$ & $0.80 \pm 0.03 b$ \\
\hline
\end{tabular}

Significant tests $B$. carinata

$\begin{array}{lll}\text { Cropping }(C) & \text { ns } & \text { ns } \\ \text { Irrigation }(l) & \text { ns } & * \\ C \times I & \text { ns } & *\end{array}$

Significant tests S. scabrum

Cropping $(C)$
Irrigation $(l)$
$\quad C \times I$

For treatment description, see Table 1. Shown are the mean values $(n=4)$ obtained for each treatment \pm standard deviation. Values in a column followed by the same

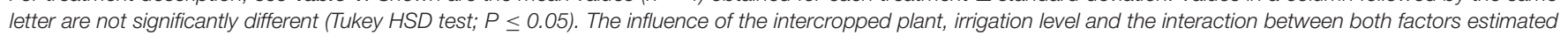
by a two-way ANOVA are also presented. ns: not significant; *: significant at $P \leq 0.05$.

\section{Changes in Leaf Glucosinolates Concentration in B. carinata}

The prevalence of the 2-propenyl glucosinolate in the glucosinolate profile of $B$. carinata was also demonstrated by other B. carinata accessions (Schreiner et al., 2009) suggesting the dominance of this aliphatic glucosinolate as specific characteristic of B. carinata. However, the B. carinata accession in the presented study (arumeru, Tanzania) was unaffected by reduced water supply, which is in contrast to other B. carinata accessions originating from Ethiopian (Holeta-1 and 37-A), and showing a distinct accumulation in 2-propenyl glucosinolate in the leaves under drought (Schreiner et al., 2009). Also in B. juncea, a Brassica species with 2-propenyl glucosinolate as major glucosinolate, topsoil drying caused a clear increase in the 
concentration of the predominant 2-propenyl glucosinolate in leaves and roots (Tong et al., 2014).

It could be assumed that there might be a Brassica speciesspecific as well as $B$. carinata accession-specific sensibility to the reduction of water supply suggesting a genotypic variation in the responsiveness to the drought-induced formation of abscisic acid as root-to-shoot signaling for increased aliphatic glucosinolate biosynthesis (Tong et al., 2014). This assumption is supported by Chen et al. (2012) who confirmed that the glucosinolate metabolism is linked to the plant's hormone network including abscisic acid.

As seen in the aliphatic 2-propenyl glucosinolate, it seems that also all individual indole glucosinolates are not participating in plant responses to abiotic stress such as drought. They showed no response to the variation in the water supply conditions, which again is partly adversative to the drought reaction of the Ethiopian B. carinata accessions (Schreiner et al., 2009) and topsoil dried B. juncea (Tong et al., 2014). In these drought stress studies the 3-indolylmethyl glucosinolate in leaves increased at severely reduced soil water content in $B$. carinata accessions or the indole glucosinolates 3-indolylmethyl and 4-methoxy3-indolylmethyl decreased under topsoil drying in B. juncea. However, all other indole glucosinolates were unaffected by the soil water conditions.

As found in our study in B. carinata, limited water supply did not affect indole glucosinolates in $B$. rapa ssp. rapifera (Zhang et al., 2008), whereas it increased indole glucosinolate concentration in leaves of B. oleracea (Radovich et al., 2005) and decreased it in B. oleracea var. italica (Robbins et al., 2005), suggesting genotypically different responses to drought also in respect to indole glucosinolates.

By intercropping an indigenous brassicaceous species (B. carinata) with a solanaceous species (S. scabrum), we specifically addressed the question of whether interactive effects of intercropping on the glucosinolate status in $B$. carinata occur under controlled condition. The aliphatic 2-propenyl glucosinolate distinctly increased under optimal water supply when intercropped with S. scabrum. Also the indole glucosinolate 4-hydroxy-3-indolylmethyl increased by intercropping under optimal water conditions, but in a less pronounced response. This increase in aliphatic glucosinolate concentration was probably mediated by interspecific competition resulting from root overlap of both species within intercropping and leading to an induced accumulation especially of the predominant 2-propenyl glucosinolate. Similar results have been reported by Björkman et al. (2008) on white cabbage intercropped with red clover. In contrast, when broccoli (Brassica oleracea var. italica) was grown with sesame (Sesamum indicum), the major aliphatic glucosinolate in broccoli, 4-methylsulphinylbutyl glucosinolate concentration was not affected by the neighboring sesame plant (Tong et al., 2015). This may indicate a certain level of specificity in plant responses to biotic stress (Kuhlmann and Müller, 2009), and the differences in the aliphatic glucosinolate formation in response to intercropping could be species-specific, or a typical structure-specific response to abiotic stress as it was found in Brassica (Mewis et al., 2012).

\section{Changes in Leaf Carotenoids and Chlorophyll Concentration}

Both carotenoids and chlorophylls are largely influenced by genetic variation and growing conditions. Previous studies revealed an impact of intercropping on carotenoids as well as chlorophylls in various crops, e.g., amaranth leaves (Ng'ang'a et al., 2009), carrots (Jankowska et al., 2012), Chinese cabbage (Cai et al., 2011), and Moringa (Abou-Zeid and Salama, 2014). In our study the intercropping did not significantly change the concentration of the photosynthetic pigments, whereas the water supply impacted their concentration. While in B. carinata the chlorophyll b concentration was lower under water deficiency, higher levels for lutein as well as chlorophyll a and chlorophyll b have been detected under reduced water supply in S. scabrum. Drought induces the production of ROS (Hasegawa et al., 2000) and the lipophilic, antioxidant carotenoids help protecting membranes from damage (Havaux, 1998). Carotene accumulation in plants is consequently influenced by plant water status. It suggests that the $B$. carinata shows a higher adaptation to drought, since fewer changes have been observed in our study. Moreover, the B. carinata responds by accumulating specific glucosinolates, which cannot be found in S. scabrum. Although the influence of drought on photosynthetic pigments in vegetables has not been fully assessed yet, contrasting results have also been reported either showing a reduction or an increase of pigments, e.g., decreased chlorophyll or carotenoid concentrations have been reported in pepper (MenaViolante et al., 2006) or chickpea (Sohrabi et al., 2012) and increased pigment concentrations in tomato (Giannakoula and Ilias, 2013). The interaction observed between drought and intercropping are an interesting finding and could be an important issue for drought stress management strategies and hence, improve water-use efficiency by constant or increased carotenoid concentrations.

\section{Flavonoid Diversity}

The flavonoid glycosides and hydroxycinnamic acid derivative profiles of B. carinata and S. scabrum are consistent to previous studies where these compounds were identified in indigenous African vegetables (Neugart et al., 2017). It can be concluded that the profiles differ enormously between the two crops. In the present study hydroxycinnamic acids and flavonoid glycoside derivatives such as caffeic acid, coumaric acid, ferulic acid, hydroxyferulic, sinapic acid, isorhamnetin, kaempferol, and quercetin derivatives were quantified in B. carinata and S. scabrum (Nilsson et al., 2006; El-Seedi et al., 2012). Many flavonoid glycoside derivatives we identified in B. carinata were previously found in B. oleracea plants (Schmidt et al., 2010). In B. carinata, fifteen different flavonoid glycosides were quantified, of which, four isorhamnetin, nine kaempferol and two quercetin glycosides, with few significant differences found. The most common flavonoid glycosides found in Brassica are kaempferol glycosides (Nielsen et al., 1998; Chun et al., 2004; Mann and Khanna, 2013). However, B. carinata contains remarkable concentrations of isorhamnetin glycosides compared to $B$. oleracea species. Mainly kaempferol glycosides were 
decreased by intercropping and low irrigation. Also, on five different hydroxycinnamic acids quantified, intercropping and low irrigation had a reducing effect. These acids were found to have similar concentration in $B$. carinata plants, compared to $B$. oleracea plants (El-Seedi et al., 2012). Studies reported by Ashraf and Mehmood (1990) on selected Brassica, state that B. carinata is sensitive to drought stress.

From the studies done by Lewis et al. (1998), most common flavonoid derivatives found in Solanum tuberosum are kaempferol and quercetin glycoside, similar to that of S. scabrum in the present study. There were four kaempferol and ten quercetin glycosides found in S. scabrum, these are the most commonly found flavonoid glycosides in Solanum species (Lewis et al., 1998). The amount of kaempferol and quercetin glycosides were found to be more in S. scabrum compared to Solanum lycopersicum (Bovy et al., 2007). Of the eight different hydroxycinnamic acids found in S. scabrum, most of them were decreased with water reduction. From the studies reported by ElSeedi et al. (2012), commonly found hydroxycinnamic acids were caffeic and sinapic acids, wherein, the amount of caffeic acids were relatively similar in $S$. scabrum compared to $S$. lycopersicum and S. melongena. Sinapic acid was, however, identified in S. scabrum, and not previously identified in S. lycopersicum and S. melongena.

Mainly kaempferol glycosides and hydroxycinnamic acid derivatives of $B$. carinata and $S$. scabrum were decreased by intercropping and irrigation system. The total flavonoids of marigold and faba bean were not affected by intercropping with lettuce and maize, respectively (Li et al., 2012; Fonseca et al., 2016). However, there is evidence that the response is structure-dependent. Quercetin and kaempferol in faba bean were not affected by the intercropping with maize whereas luteolin was increased ( $\mathrm{Li}$ et al., 2012). Referring to the results of the current study it can be suggested that a decrease of flavonoid glycosides and hydroxycinnamic acids due to intercropping is true for different species such as B. carinata and S. scabrum. The underlying mechanism is not clear yet.

In a number of species total phenolics or total flavonoids were not affected by the reduction of water by $50 \%$ (Sangtarash et al., 2009; Bernal et al., 2013). However, in a more detailed view specific hydroxycinnamic acid derivatives and quercetin as well as kaempferol glycosides are decreased due to drought in Ligustrum vulgare (Tattini et al., 2004), different citrus species (Zandalinas et al., 2016) and Vitis vinifera (Alonso et al., 2015). These species are common in the Mediterranean and other warm regions and might be adapted to drought periods during their growth. Also the plants in our experiment are used to higher temperatures and therefore the decrease in hydroxycinnamic acid derivatives and quercetin and kaempferol glycosides is consistent with the literature. André et al. (2009) demonstrated that the effect of drought on the chlorogenic acid and kaempferol-3-rutinoside of various potato cultivars is dependent on the cultivar. While three cultivars showed decreases in the before mentioned compounds one did not respond and one showed an increase. Nevertheless, the quercetin glycosides known for their higher antioxidant activity (Zietz et al., 2010) were not affected by the drought. This could explain why in the present experiment mainly hydroxycinnamic acid derivatives and kaempferol glycosides were decreased due to drought.

\section{CONCLUSION}

Intercropping had no effect on biomass production or mineral nutrient uptake in both $B$. carinata and S. scabrum and no clear belowground competition/complementation for mineral nutrient uptake was evident under our experimental conditions. It, however, led to changes in the concentration of specific health related secondary metabolites. Intercropping $B$. carinata and $S$. scabrum led to increase in total glucosinolate content in $B$. carinata while maintaining biomass production and other health related minerals in both species. Low irrigation led to an increase in carotene accumulation in both mono and intercropped $S$. scabrum, but not in $B$. carinata. In contrast, mainly kaempferol glycosides and hydroxycinnamic acid derivatives of $B$. carinata and S. scabrum were decreased by intercropping and drought treatment.

This study indicates that some health-related phytochemicals can be modified by intercropping or late-season drought, however, field validation of these results is necessary before definite recommendation can be made to stakeholders.

\section{AUTHOR CONTRIBUTIONS}

$\mathrm{BN}$ : Contributed in conception and design, analysis, interpretation of data; drafting and revising content; final approval of the version to be published; agreement to be accountable for all aspects of the work. SN and SB: Contributed in conception, analysis, interpretation of data; drafting and revising content; final approval of the version to be published; agreement to be accountable for all aspects of the work. BR: Contributed in analysis, interpretation of data; revising content; final approval of the version to be published; agreement to be accountable for all aspects of the work. MS: Contributed in conception and design, interpretation of data; drafting and revising content; final approval of the version to be published; agreement to be accountable for all aspects of the work.

\section{ACKNOWLEDGMENTS}

The present work was financially supported as part of the project "Horticultural Innovation and Learning for Improved Nutrition and Livelihood in East Africa" (FKZ 031A248J), funded within the global food security (GlobE) initiative of the German Federal Ministry of Education and Research and the German Federal Ministry for Economic Cooperation and Development.

\section{SUPPLEMENTARY MATERIAL}

The Supplementary Material for this article can be found online at: http://journal.frontiersin.org/article/10.3389/fpls.2017.01700/ full\#supplementary-material 


\section{REFERENCES}

Abou-Zeid, H. M., and Salama, M. (2014). Biological interactions between Moringa oleifera Lam. and two common food intercrops: growth and some physiological attributes. Int. J. 2, 823-836.

Abukutsa, M. O. O. (2010). African Indigenous Vegetables in Kenya: Strategic Repositioning in the Horticultural Sector. Kanya: Jomo Kenyatta University of Agriculture and Technology.

AFSA (2016). Agroecology: The Bold Future of Farming in Africa. Available at: http://afsafrica.org/agroecology-the-bold-future- of-farming-in-africa/

Alonso, R., Berli, F. J., Bottini, R., and Piccoli, P. (2015). Acclimation mechanisms elicited by sprayed abscisic acid, solar UV-B and water deficit in leaf tissues of field-grown grapevines. Plant Physiol. Biochem. 91, 56-60. doi: 10.1016/j. plaphy.2015.03.011

Ambrose-Oji, B. (2009). "Urban food systems and African indigenous vegetables: defining the spaces and places for African indigenous vegetables in urban and peri-urban agriculture," in African Indigenous Vegetables in Urban Agriculture, eds M. Shackleton, M. W. Pasquini, and A. W. Drescher (London: Earthscan), $1-33$.

André, C. M., Schafleitner, R., Legay, S., Lefèvre, I., Aliaga, C. A. A., Nomberto, G., et al. (2009). Gene expression changes related to the production of phenolic compounds in potato tubers grown under drought stress. Phytochemistry 70, 1107-1116. doi: 10.1016/j.phytochem.2009.07.008

Ashraf, M., and Mehmood, S. (1990). Response of four Brassica species to drought stress. Environ. Exp. Bot. 30, 93-100. doi: 10.1016/0098-8472(90)90013-T

Baldermann, S., Blagojeviæ, L., Frede, K., Klopsch, R., Neugart, S., Neumann, A., et al. (2016). Are neglected plants the food for the future? Crit. Rev. Plant Sci. 35, 106-119. doi: 10.1080/07352689.2016.1201399

Bernal, M., Llorens, L., Badosa, J., and Verdaguer, D. (2013). Interactive effects of UV radiation and water availability on seedlings of six woody Mediterranean species. Physiol. Plant. 147, 234-247. doi: 10.1111/j.1399-3054.2012.01660.x

Björkman, M., Hopkins, R. J., and Rämert, B. (2008). Combined effect of intercropping and turnip root fly (Delia floralis) larval feeding on the glucosinolate concentrations in cabbage roots and foliage. J. Chem. Ecol. 34, 1368-1376. doi: 10.1007/s10886-008-9533-0

Bovy, A., Schijlen, E., and Hall, R. D. (2007). Metabolic engineering of flavonoids in tomato (Solanum lycopersicum): the potential for metabolomics. Metabolomics 3, 399-412. doi: 10.1007/s11306-007-0074-2

Burke, M. B., Lobell, D. B., and Guarino, L. (2009). Shifts in African crop climates by 2050 , and the implications for crop improvement and genetic resources conservation. Glob. Environ. Change 19, 317-325. doi: 10.1016/j.gloenvcha. 2009.04.003

Cai, H., You, M., Ryall, K., Li, S., and Wang, H.-Y. (2011). Physiological response of Chinese cabbage to intercropping systems. Agron. J. 103, 331-336. doi: 10. 2134/agronj2010.0337

Cernansky, R. (2015). The rise of Africa's super vegetables. Nature 522, 146-148. doi: 10.1038/522146a

Chen, Y.-Z., Pang, Q.-Y., He, Y., Zhu, N., Branstrom, I., Yan, X.-F., et al. (2012). Proteomics and metabolomics of Arabidopsis responses to perturbation of glucosinolate biosynthesis. Mol. Plant 5, 1138-1150. doi: 10.1093/mp/ sss034

Chun, O. K., Smith, N., Sakagawa, A., and Lee, C. Y. (2004). Antioxidant properties of raw and processed cabbages. Int. J. Food Sci. Nutr. 55, 191-199. doi: 10.1080/ 09637480410001725148

Ehrmann, J., and Ritz, K. (2014). Plant: soil interactions in temperate multicropping production systems. Plant Soil 376, 1-29. doi: 10.1007/s11104-0131921-8

El-Seedi, H. R., El-Said, A. M., Khalifa, S. A., Göransson, U., Bohlin, L., BorgKarlson, A.-K., et al. (2012). Biosynthesis, natural sources, dietary intake, pharmacokinetic properties, and biological activities of hydroxycinnamic acids. J. Agric. Food Chem. 60, 10877-10895. doi: 10.1021/jf301807g

FAO (2015). Regional Overview of Food Insecurity: African Food Security Prospects Brighter than Ever. Rome: Food and Agriculture Organization Publications.

Fonseca, M. C. M., Sediyama, M. A. N., Bonfim, F. P. G., Dores, R. G. R. D., Gonçalves, M. G., Prado, A. L. D., et al. (2016). Lettuce and marigold intercropping: crops productivity and marigold's flavonoid content. Ciên. Rural 46, 1553-1558. doi: 10.1590/0103-8478cr20150712
Frison, E. (2016). From Uniformity to Diversity: A Paradigm Shift from Industrial Agriculture to Diversified Agroecological Systems. Brussels: International Panel of Experts on Sustainable Food systems.

Gericke, S., and Kurmies, B. (1952). Die kolorimetrische phosphorsäurebestimmung mit ammonium-vanadat-molybdat und ihre Anwendung in der Pflanzenanalyse. Z. Düngg. Pflanzenernähr. Bodenkunde 59, 235-247.

Giannakoula, A. E., and Ilias, I. (2013). The effect of water stress and salinity on growth and physiology of tomato (Lycopersicon esculentum Mil.). Arch. Biol. Sci. 65, 611-620. doi: 10.2298/ABS1302611G

Guzmán-Pérez, V., Bumke-Vogt, C., Schreiner, M., Mewis, I., Borchert, A., and Pfeiffer, A. F. (2016). Benzylglucosinolate derived isothiocyanate from Tropaeolum majus reduces gluconeogenic gene and protein expression in human cells. PLOS ONE 11:e0162397. doi: 10.1371/journal.pone.0162397

Hasegawa, P. M., Bressan, R. A., Zhu, J.-K., and Bohnert, H. J. (2000). Plant cellular and molecular responses to high salinity. Annu. Rev. Plant Biol. 51, 463-499. doi: 10.1146/annurev.arplant.51.1.463

Hauggaard-Nielsen, H., Jørnsgaard, B., Kinane, J., and Jensen, E. S. (2008). Grain legume-cereal intercropping: the practical application of diversity, competition and facilitation in arable and organic cropping systems. Renew. Agric. Food Syst. 23, 3-12. doi: 10.1017/S1742170507002025

Havaux, M. (1998). Carotenoids as membrane stabilizers in chloroplasts. Trends Plant Sci. 3, 147-151. doi: 10.1016/S1360-1385(98)01200-X

Herz, C., Márton, M.-R., Tran, H. T. T., Gründemann, C., Schell, J., and Lamy, E. (2016). Benzyl isothiocyanate but not benzyl nitrile from Brassicales plants dually blocks the COX and LOX pathway in primary human immune cells. J. Funct. Foods 23, 135-143. doi: 10.1016/j.jff.2016.02.034

IFAD (ed.). (2011). “The importance of addressing risk," in Rural Poverty Report 2011: New realities, new challenges: new opportunities for tomorrow's generation. Rome: IFAD. 72-109.

Inal, A., and Gunes, A. (2008). Interspecific root interactions and rhizosphere effects on salt ions and nutrient uptake between mixed grown peanut/maize and peanut/barley in original saline-sodic-boron toxic soil. J. Plant Physiol. 165, 490-503. doi: 10.1016/j.jplph.2007.01.016

Inal, A., Gunes, A., Zhang, F., and Cakmak, I. (2007). Peanut/maize intercropping induced changes in rhizosphere and nutrient concentrations in shoots. Plant Physiol. Biochem. 45, 350-356. doi: 10.1016/j.plaphy.2007.03.016

Jankowska, B., Jedrszczyk, E., and Poniedzialek, M. (2012). Effect of intercropping carrot (Daucus carota L.) with French marigold (Tagetes patula nana L.) and pot marigold (Calendula officinalis L.) on the occurrence of some petsts and quality of carrot yield. Acta Agrobot. 65, 133-138. doi: 10.5586/aa.2012.030

Khan, Z. R., Midega, C. A., Bruce, T. J., Hooper, A. M., and Pickett, J. A. (2010). Exploiting phytochemicals for developing a 'push-pull'crop protection strategy for cereal farmers in Africa. J. Exp. Bot. 61, 4185-4196. doi: 10.1093/jxb/erq229

Kuhlmann, F., and Müller, C. (2009). Independent responses to ultraviolet radiation and herbivore attack in broccoli. J. Exp. Bot. 60, 3467-3475. doi: $10.1093 /$ jxb/erp182

Lartey, A. (2015). End hunger, achieve food security and improved nutrition and promote sustainable agriculture. UN Chron. 51, 6-8. doi: 10.18356/5940 d90a-en

Lewis, C. E., Walker, J. R., Lancaster, J. E., and Sutton, K. H. (1998). Determination of anthocyanins, flavonoids and phenolic acids in potatoes. I: coloured cultivars of Solanum tuberosum L. J. Sci. Food Agric. 77, 45-57. doi: 10.1002/(SICI)10970010(199805)77:1<45::AID-JSFA1>3.0.CO;2-S

Li, B., Krumbein, A., Neugart, S., Li, L., and Schreiner, M. (2012). Mixed cropping with maize combined with moderate UV-B radiations lead to enhanced flavonoid production and root growth in faba bean. J. Plant Interact. 7, 333-340. doi: 10.1080/17429145.2012.714407

Li, L., Tilman, D., Lambers, H., and Zhang, F. S. (2014). Plant diversity and overyielding: insights from belowground facilitation of intercropping in agriculture. New Phytol. 203, 63-69. doi: 10.1111/nph.12778

Lippmann, D., Lehmann, C., Florian, S., Barknowitz, G., Haack, M., Mewis, I., et al. (2014). Glucosinolates from pak choi and broccoli induce enzymes and inhibit inflammation and colon cancer differently. Food Funct. 5, 1073-1081. doi: $10.1039 / \mathrm{c} 3$ fo60676g

Lisar, S. Y., Rahman, I. M., Hossain, M. M., and Motafakkerazad, R. (2012). "Water stress in plants: causes, effects and responses," in Water Stress, eds I. M. M. Rahman and H. Hasegawa (Rijeka: INTECH Open Access Publisher), 1-14. 
Lithourgidis, A., Dordas, C., Damalas, C., and Vlachostergios, D. (2011). Annual intercrops: an alternative pathway for sustainable agriculture. Aust. J. Crop Sci. 5, 396-410.

Mann, S. K., and Khanna, N. (2013). Health promoting effects of phytochemicals from brassicaceae: a review. Indian J. Pharm. Biol. Res. 1, 120-131.

Martin, M., and Snaydon, R. (1982). Root and shoot interactions between barley and field beans when intercropped. J. Appl. Ecol. 19, 263-272. doi: 10.2307/ 2403009

Mena-Violante, H. G., Ocampo-Jiménez, O., Dendooven, L., Martínez-Soto, G., González-Castañeda, J., Davies, F. T., et al. (2006). Arbuscular mycorrhizal fungi enhance fruit growth and quality of chile ancho (Capsicum annuum $\mathrm{L}$. cv San Luis) plants exposed to drought. Mycorrhiza 16, 261.

Mewis, I., Schreiner, M., Nguyen, C. N., Krumbein, A., Ulrichs, C., Lohse, M., et al. (2012). UV-B irradiation changes specifically the secondary metabolite profile in broccoli sprouts: induced signaling overlaps with defense response to biotic stressors. Plant Cell Physiol. 53, 1546-1560. doi: 10.1093/pcp/pcs096

Neugart, S., Baldermann, S., Ngwene, B., Wesonga, J., and Schreiner, M. (2017). Indigenous leafy vegetables of Eastern Africa - a source of extraordinary secondary plant metabolites. Food Res. Int. (in press). doi: 10.1016/j.foodres. 2017.02.014

Neugart, S., Rohn, S., and Schreiner, M. (2015). Identification of complex, naturally occurring flavonoid glycosides in Vicia faba and Pisum sativum leaves by HPLCDAD-ESI-MSn and the genotypic effect on their flavonoid profile. Food Res. Int. 76, 114-121. doi: 10.1016/j.foodres.2015.02.021

Ng'ang'a, M., Muasya, R., Omami, E., and Ohiokpehai, O. (2009). Effect of environment, intercropping systems and harvest intervals on protein and $\beta$-carotene contents of leaf amaranth. Acta Hortic. 911, 433-436.

Nielsen, J. K., Nørbæk, R., and Olsen, C. E. (1998). Kaempferol tetraglucosides from cabbage leaves. Phytochemistry 49, 2171-2176. doi: 10.1016/S0031-9422(98) 00422-1

Nilsson, J., Olsson, K., Engqvist, G., Ekvall, J., Olsson, M., Nyman, M., et al. (2006). Variation in the content of glucosinolates, hydroxycinnamic acids, carotenoids, total antioxidant capacity and low-molecular-weight carbohydrates in brassica vegetables. J. Sci. Food Agric. 86, 528-538. doi: 10.1002/jsfa.2355

Noorani, A., Nono-Womdim, R., Padulosi, S., and Ngwene, B. (2016). Interventions for mainstreaming underutilized crop species in developing regions. Acta Hortic. 1128, 21-28. doi: 10.17660/ActaHortic.2016. 1128.4

Odongo, G. A., Schlotz, N., Herz, C., Hanschen, F. S., Baldermann, S., Neugart, S., et al. (2017). The role of plant processing for the cancer preventive potential of Ethiopian kale (Brassica carinata). Food Nutr. Res. 61:1271527. doi: 10.1080/ 16546628.2017.1271527

Olasantan, F. (2007). Vegetable production in tropical Africa: status and strategies for sustainable management. J. Sustain. Agric. 30, 41-70. doi: 10.1300/ J064v30n03_05

Omondi, E. O., Engels, C., Nambafu, G., Schreiner, M., Neugart, S., AbukutsaOnyango, M., et al. (2017). Nutritional compound analysis and morphological characterization of spider plant (Cleome gynandra) - an African indigenous leafy vegetable. Food Res. Int. 100(Pt 1), 284-295. doi: 10.1016/j.foodres.2017. 06.050

Onyango, C., and Imungi, J. (2007). Postharvest handling and characteristics of fresh-cut traditional vegetables sold in Nairobi-Kenya. Afr. Crop Sci. Conf. Proceed. 8, 1791-1794.

Oseko, J., Onyango, M. A., and Onyango, J. (2006). "Performance of African kale (Brassica carinata) to intercropping with other Indigenous Vegetables," in Proceedings of the Fifth Workshop on Sustainable Horticultural Production in the Tropics, eds D. K. Isutsa, J. M. Wesonga, M. O. A. Onyango, J. B. M. Njoroge, M. M. Waiganjo, S. G. Agong, et al. (Njoro: Egerton University), 235-250.

Prasad, T. K., Anderson, M. D., Martin, B. A., and Stewart, C. R. (1994). Evidence for chilling-induced oxidative stress in maize seedlings and a regulatory role for hydrogen peroxide. Plant Cell 6, 65-74. doi: 10.1105/tpc.6.1.65

Radovich, T. J., Kleinhenz, M. D., and Streeter, J. G. (2005). Irrigation timing relative to head development influences yield components, sugar levels, and glucosinolate concentrations in cabbage. J. Am. Soc. Hortic. Sci. 130, 943-949.

Raseduzzaman, M. (2016). Intercropping for Enhanced Yield Stability and Food Security. Uppsala: Swedish university of agricultural sciences.
Robbins, R. J., Keck, A.-S., Banuelos, G., and Finley, J. W. (2005). Cultivation conditions and selenium fertilization alter the phenolic profile, glucosinolate, and sulforaphane content of broccoli. J. Med. Food 8, 204-214. doi: 10.1089/ jmf.2005.8.204

Sangtarash, M., Qaderi, M., Chinnappa, C., and Reid, D. (2009). Differential sensitivity of canola (Brassica napus) seedlings to ultraviolet-B radiation, water stress and abscisic acid. Environ. Exp. Bot. 66, 212-219. doi: 10.1016/j. envexpbot.2009.03.004

Schmidt, S., Zietz, M., Schreiner, M., Rohn, S., Kroh, L. W., and Krumbein, A. (2010). Identification of complex, naturally occurring flavonoid glycosides in kale (Brassica oleracea var. sabellica) by high-performance liquid chromatography diode-array detection/electrospray ionization multistage mass spectrometry. Rapid Commun. Mass Spectrom. 24, 2009-2022. doi: $10.1002 / \mathrm{rcm} .4605$

Schreiner, M., Beyene, B., Krumbein, A., and Stützel, H. (2009). Ontogenetic changes of 2-propenyl and 3-indolylmethyl glucosinolates in Brassica carinata leaves as affected by water supply. J. Agric. Food Chem. 57, 7259-7263. doi: $10.1021 / \mathrm{jf} 901076 \mathrm{~h}$

Shen, J., Li, C., Mi, G., Li, L., Yuan, L., Jiang, R., et al. (2012). Maximizing root/rhizosphere efficiency to improve crop productivity and nutrient use efficiency in intensive agriculture of China. J. Exp. Bot. 64, 1181-1192. doi: 10.1093/jxb/ers342

Sohrabi, Y., Heidari, G., Weisany, W., Golezani, K. G., and Mohammadi, K. (2012). Changes of antioxidative enzymes, lipid peroxidation and chlorophyll content in chickpea types colonized by different Glomus species under drought stress. Symbiosis 56, 5-18. doi: 10.1007/s13199-012-0152-8

Tattini, M., Galardi, C., Pinelli, P., Massai, R., Remorini, D., and Agati, G. (2004). Differential accumulation of flavonoids and hydroxycinnamates in leaves of Ligustrum vulgare under excess light and drought stress. New Phytol. 163, 547-561. doi: 10.1111/j.1469-8137.2004.01126.x

Tong, Y., Gabriel-Neumann, E., Krumbein, A., Ngwene, B., George, E., and Schreiner, M. (2015). Interactive effects of arbuscular mycorrhizal fungi and intercropping with sesame (Sesamum indicum) on the glucosinolate profile in broccoli (Brassica oleracea var. Italica). Environ. Exp. Bot. 109, 288-295. doi: 10.1016/j.envexpbot.2014.06.008

Tong, Y., Gabriel-Neumann, E., Ngwene, B., Krumbein, A., George, E., Platz, S., et al. (2014). Topsoil drying combined with increased sulfur supply leads to enhanced aliphatic glucosinolates in Brassica juncea leaves and roots. Food Chem. 152, 190-196. doi: 10.1016/j.foodchem.2013.11.099

Uauy, R. (2016). "Towards a balanced "healthy diet" for the 21st Century," in Good Nutrition: Perspectives for the 21st Century, eds M. Eggersdorfer, K. Kraemer, J. B. Cordaro, J. Fanzo, M. Gibney, E. Kennedy, et al. (New York, NY: Karger), 60-69.

Uusiku, N. P., Oelofse, A., Duodu, K. G., Bester, M. J., and Faber, M. (2010). Nutritional value of leafy vegetables of sub-Saharan Africa and their potential contribution to human health: a review. J. Food Compos. Anal. 23, 499-509. doi: 10.1016/j.jfca.2010.05.002

Verkerk, R., Schreiner, M., Krumbein, A., Ciska, E., Holst, B., Rowland, I., et al. (2009). Glucosinolates in Brassica vegetables: the influence of the food supply chain on intake, bioavailability and human health. Mol. Nutr. Food Res. 53, S219-S219. doi: 10.1002/mnfr.200800065

Wang, D., Marschner, P., Solaiman, Z., and Rengel, Z. (2007). Belowground interactions between intercropped wheat and Brassicas in acidic and alkaline soils. Soil Biol. Biochem. 39, 961-971. doi: 10.1016/j.soilbio.2006. 11.008

Wang, Z.-G., Jin, X., Bao, X.-G., Li, X.-F., Zhao, J.-H., Sun, J.-H., et al. (2014). Intercropping enhances productivity and maintains the most soil fertility properties relative to sole cropping. PLOS ONE 9:e113984. doi: 10.1371/journal. pone. 0113984

Wiesner, M., Zrenner, R., Krumbein, A., Glatt, H., and Schreiner, M. (2013). Genotypic variation of the glucosinolate profile in pak choi (Brassica rapa ssp. chinensis). J. Agric. Food Chem. 61, 1943-1953. doi: 10.1021/jf30 $3970 \mathrm{k}$

Yang, R.-Y., and Keding, G. B. (2009). "Nutritional contributions of important African indigenous vegetables," in African Indigenous Vegetables in Urban Agriculture, eds M. Shackleton, M. W. Pasquini, and A. W. Drescher (London: Earthscan), 105-143. 
Zandalinas, S. I., Sales, C., Beltran, J., Gomez-Cadenas, A., and Arbona, V. (2016). Activation of secondary metabolism in citrus plants is associated to sensitivity to combined drought and high temperatures. Front. Plant Sci. 7:1954. doi: 10.3389/fpls.2016.01954

Zarea, M. J., Ghalavand, A., Goltapeh, E. M., Rejali, F., and Zamaniyan, M. (2009). Effects of mixed cropping, earthworms (Pheretima sp.), and arbuscular mycorrhizal fungi (Glomus mosseae) on plant yield, mycorrhizal colonization rate, soil microbial biomass, and nitrogenase activity of free-living rhizosphere bacteria. Pedobiologia 52, 223-235. doi: 10.1016/j.pedobi.2008. 10.004

Zhang, H., Schonhof, I., Krumbein, A., Gutezeit, B., Li, L., Stützel, H., et al. (2008). Water supply and growing season influence glucosinolate concentration and composition in turnip root (Brassica rapa ssp. rapifera L.). J. Plant Nutr. Soil Sci. 171, 255-265. doi: 10.1002/jpln.200700079

Zietz, M., Weckmüller, A., Schmidt, S., Rohn, S., Schreiner, M., Krumbein, A., et al. (2010). Genotypic and climatic influence on the antioxidant activity of flavonoids in kale (Brassica oleracea var. sabellica). J. Agric. Food Chem. 58, 2123-2130. doi: 10.1021/jf9033909

Conflict of Interest Statement: The authors declare that the research was conducted in the absence of any commercial or financial relationships that could be construed as a potential conflict of interest.

The reviewer ST and handling Editor declared their shared affiliation.

Copyright (c) 2017 Ngwene, Neugart, Baldermann, Ravi and Schreiner. This is an open-access article distributed under the terms of the Creative Commons Attribution License (CC BY). The use, distribution or reproduction in other forums is permitted, provided the original author(s) or licensor are credited and that the original publication in this journal is cited, in accordance with accepted academic practice. No use, distribution or reproduction is permitted which does not comply with these terms. 